\title{
Chapter 31 \\ Singapore's Experience in Analyzing the Labor Market Using Artificial Intelligence and Big Data Analytics
}

\author{
Gary Gan
}

The Fourth Industrial Revolution, or Industry 4.0, has brought about rapid changes in the world of work. Digital technologies such as artificial intelligence (AI) and robotics have disrupted major industries, and jobs are evolving faster than ever before.

Around $60 \%$ of today's job roles entail at least $30 \%$ of tasks that can be automated, ${ }^{1}$ and around a quarter of today's job roles have more than $70 \%$ of automatable tasks. Even $28 \%$ of reasoning and decision-making, a traditionally human work function, is expected to be performed by machines in $2022 .^{2}$ At the rate that technology is evolving, it is difficult to determine how long one can continue to be relevant.

In earlier years, Singapore focused more on developing the education system for pre-employment education, with Singapore ranking first in terms of the World Bank's Human Capital Index. Now, there is an increasing focus on helping Singaporean workers stay competitive postemployment, through workforce transformation and lifelong learning, to help workers cope with the changing requirements in the world of work.

\footnotetext{
${ }^{1}$ A Future That Works: Automation, Employment, and Productivity. 2017. Retrieved February 28, 2019 from https://www.mckinsey.com/ /media/mckinsey/featured insights/Digital Disruption/Harnessing automation for a future that works/MGI-A-future-that-works-Executivesummary.ashx.

${ }^{2}$ The Future of Jobs Report 2018. 2018. World Economic Forum, 10-14. Retrieved February 28, 2019, from http://www3.weforum.org/docs/WEF_Future_of_Jobs_2018.pdf.
}

G. Gan $(\varangle)$

JobKred, Singapore, Singapore

e-mail: garyganchiahuey@gmail.com

B. Panth and R. Maclean (eds.), Anticipating and Preparing for Emerging Skills and Jobs, Education in the Asia-Pacific Region: Issues, Concerns and Prospects 55, https://doi.org/10.1007/978-981-15-7018-6_31 


\section{Breakdown of Challenges}

To keep up with technological changes, workers need to adopt both on-the-job experience and active reskilling. The change in mindsets of the workforce is evident: Globally, the number of learners taking massive open online courses (MOOCs) increased from 35 million in 2015 to 101 million in $2018 .^{3,4}$ In Singapore, the number of adult learners engaging in course offerings by the five national polytechnics also increased to 77,000 in 2017.5

However, challenges still exist in face of these trends. Some of the key barriers to effective workforce upgrading lie in understanding labor market trends and getting sufficient buy-in from both workers and businesses.

\section{Real-Time Awareness of Labor Market Skills Demand}

Policymakers, businesses, and individuals need to understand the rapid changes in industry skills demand in today's digital economy in order to inform their planning and decision making. Traditionally, this process involved consulting industry professionals to provide a well-researched perspective and forecast of the future. However, the difficulty of this task has grown with the rate of labor market changes.

Businesses and individual workers face information failure when planning for workforce shifts and the accompanying training initiatives. American organizations spent an average of $\$ 1,252$ per employee on training and development initiatives in 2015 , totaling more than $\$ 350$ billion for the year. ${ }^{6}$ Yet, $92 \%$ of executives agree that there is a skills gap in the United States workforce. ${ }^{7}$ The lack of benefits from learning and development investments stems largely from untargeted training and the lack of a common skills language among the market, employers, and training providers.

To make sense of uncertainty, and keep up with the speed of labor market information, technologies to consolidate the latest information and identify deeper trends need to be used. A system to track the evolution of job functions and job-relevant skills needs to be implemented, and the insights generated must be simple enough for individual workers to act on them. This information will also need to be updated in

\footnotetext{
${ }^{3}$ By the Numbers: MOOCS in 2015. (2018, October 3). Retrieved February 28, 2019, from https:// www.class-central.com/report/moocs-2015-stats/.

${ }^{4}$ By the Numbers: MOOCs in 2018. (2018, December 23). Retrieved February 28, 2019 from https:// www.class-central.com/report/mooc-stats-2018/.

${ }^{5}$ Teng, A. (2017, September 11). Adult learners on the rise. Retrieved February 28, 2019, from https://www.tnp.sg/news/singapore/adult-learners-rise.

${ }^{6}$ Vox Creative (2017, November 28). Are you and your workforce ready for the future? Retrieved February 28, 2019, from https://www.recode.net/ad/16710572/workforce-digital-reskill-talent.

${ }^{7}$ The Future of Jobs Report 2018. 2018. World Economic Forum, 10-14. Retrieved February 28, 2019, from http://www3.weforum.org/docs/WEF_Future_of_Jobs_2018.pdf.
} 
real time in order to be utilized viably and will have to be able to map in the contexts of both businesses and training providers.

\section{Getting Buy-in from Enterprises and Individuals}

To keep up with shifts in the labor market, that are constantly displacing workers while creating new jobs, companies have a role to play in retraining and upskilling their workers. Maintaining a workforce with future-proof skills to complement technology and automation would naturally lead to a rise in productivity and reduce the risk of becoming irrelevant to the market.

Research demonstrates that only $30 \%$ of employees in today's at-risk job roles have received any kind of professional training over the past 12 months. Companies highlighted the lack of a clear business case and bottom-line impact for reskilling and upskilling investments as a reason for deprioritizing inclusive workforce transformation. ${ }^{8}$ Commonly used metrics to calculate training return on investment include training hours and course satisfaction level, which are not adequate to reflect what skills the company gains and how training impacts the bottom line. A metric based on skills gained, job readiness increase, and productivity increase of employees may be more valuable in presenting a clear business case for training, which could result in more training provided for employees

\section{Individuals}

Individual workers will need to proactively seek out upskilling and upgrading opportunities. Technological disruption and work automation can have different implications on high- and low-skill workers and could exacerbate the skills and employment gap between the two. Between 2002 and 2016, jobs in the United States that require low-level skills dropped from $56 \%$ to $30 \% .{ }^{9}$ Routine-based white-collared job roles such as data entry clerks and cashiers are expected to be increasingly redundant from now until 2022 due to process automation. ${ }^{10}$ Even if only a subset of their tasks is automated, a worker who lacks the appropriate skills to adapt to new technologies and perform higher value functions would naturally see their job performance and wages suppressed. As such, central to any workforce transformation strategy is

\footnotetext{
${ }^{8}$ The Future of Jobs Report 2018. 2018. World Economic Forum, 10-14. Retrieved February 28, 2019, from http://www3.weforum.org/docs/WEF_Future_of_Jobs_2018.pdf.

${ }^{9}$ The Future of Jobs Report 2018. 2018. World Economic Forum, 10-14. Retrieved February 28, 2019, from http://www3.weforum.org/docs/WEF_Future_of_Jobs_2018.pdf.

${ }^{10}$ The Future of Jobs Report 2018. 2018. World Economic Forum, 10-14. Retrieved February 28, 2019, from http://www3.weforum.org/docs/WEF_Future_of_Jobs_2018.pdf.
} 
an agile and motivated workforce that is constantly engaging in upskilling to stay future-ready and relevant.

There must be an awareness of the need to reskill, and guidance to help workers understand what skills to develop as well as what roles to transition into. A methodology of identifying and breaking down a worker's skills into a common skills language would also strengthen personal development strategies. This shared taxonomy can fill in the gaps among the worker, the labor market, and training providers.

\section{Singapore's Case Study}

In a small country like Singapore, where human capital is the greatest asset, policymakers have been racing to push out initiatives to support workforce transformation. Yet Singapore still faces a large mismatch between skills and jobs in the Southeast Asian region, mostly due to the fast pace of digital transformation in the country as compared with her neighbors. As such, the rate of displacement of workers is high, with one-fifth of Singapore's full-time workforce expected to have their jobs displaced by $2028 .^{11}$

A heartening trend is the awareness of the importance of lifelong learning among the workforce of Singapore: $83 \%$ of workers in Singapore recognized the importance of evolving and growing their skills and knowledge, along with a desire to grow their skill set as a result; $72 \%$ of workers also indicated that their biggest concern was that their knowledge and skills would become obsolete. ${ }^{12}$

The Government has capitalized on this trend and has made a number of efforts to promote upskilling and lifelong learning in the workforce, including the usage of AI and Big Data in building technology platforms for bridging skills gaps and for career counseling and guidance.

JobKred is a Singapore tech company that uses Big Data to access publicly available labor market information, informing its AI engine on the jobs and skills changes in the world of work. This AI is used in JobKred's workforce transformation platform to provide digital career guidance, skills gap analysis, and training recommendations to help individuals and employees gain skills that industry requires and prepare for the future of work.

\footnotetext{
${ }^{11}$ Technology and the future of ASEAN jobs: The impact of AI on workers in ASEAN's six largest economies. 2018. 42-48. Retrieved February 28, 2019, from https://www.cisco.com/c/dam/global/ en_sg/assets/csr/pdf/technology-and-the-future-of-asean-jobs.pdf.

${ }^{12}$ Singapore 2017 Salary Guide. 2017. 8-9. Retrieved February 28, 2019, from https://www.kellys ervices.com.sg/media/kelly-services-sg/pdf/2017singapore-salary-guide.pdf.
} 


\section{SkillsFuture Initiative}

In 2016, the Government first introduced the SkillsFuture initiative to its citizens, bringing forth a wave of upskilling programs with it. The core of the initiative is to promote and enhance the lifelong learning experience through a formal integration of skills into the contexts of various industries.

One of its most notable initiatives is the SkillsFuture Credit, wherein Singapore citizens of age 25 and above were given $\mathrm{S} \$ 500$ of credit to invest in their personal growth. This included participation in MOOCs and continuing education and training courses at local institutes. In the first 2 years after its launch, SkillsFuture Credit saw 285,000 Singapore citizens using it to take ownership of their own career pathways. ${ }^{13}$

To help citizens understand their own current skills, identify their skills gaps toward their target careers, and receive training recommendations, Singapore's national skills portal, MySkillsFuture.sg, is utilizing JobKred's AI engine, which understands current skills demand and can make relevant career and skills recommendations. This helps citizens to be more directed in their skills development journey by becoming aware of what skills to obtain in their career progression, and keeps citizens relevant to the latest skills demands.

\section{AI-Powered National Jobs Portal}

To enhance the job matching process, Singapore's national jobs portal, MyCareersFuture.sg, has implemented JobKred's technologies to power the intelligence behind every job search. Since its launch in mid-2018, there have been 250,000 active users every month, with an average of 23,000 job posts each month. ${ }^{14}$

The portal uses a data-powered approach to match a jobseeker's skills to a suitable career. JobKred first analyzes online labor market information from various sources such as job descriptions and resume data to identify emerging job titles and the relevant skills. JobKred then uses machine learning to train an AI engine to perform the job matching process.

\footnotetext{
${ }^{13}$ Technology and the future of ASEAN jobs: The impact of AI on workers in ASEAN's six largest economies. 2018. 42-48. Retrieved February 28, 2019, from https://www.cisco.com/c/dam/global/ en_sg/assets/csr/pdf/technology-and-the-future-of-asean-jobs.pdf.

${ }^{14}$ Seow, J. (2019, January 4). Better matches, more postings coming up on national job portal MyCareersFuture. Retrieved February 28, 2019, from https://www.straitstimes.com/business/eco nomy/better-matching-more-listings-on-government-job-portal.
} 


\section{Digital Career Guidance and Adaptive Curriculum}

Education institutes have also turned to systems fueled by data and machine learning for career counseling and guidance. More than half of Singapore's higher education institutes have worked with JobKred to provide students with a personalized experience. Traditionally, to understand a learner's skills and career aspirations, a lengthy and subjective profiling process would have to be carried out by the institutes. JobKred provides learners with labor market information at their fingertips and helps them to profile their current skills. Gaps are also identified between their skillsets and those in demand for their careers of interest.

This process of Skills Gap Analysis paves the way for individualized career guidance and learning. Counselors are able to profile students at scale and refer to labor market information when giving guidance, while curriculum planners can refer to aggregated data on both the students and careers in demand to perform informed decision-making in updating their curriculum.

JobKred is also working on an adaptive curriculum system, wherein curriculum and course recommendations to students change based on current labor market demand, to ensure that students are always presented with the right training that the market currently demands.

\section{Helping Enterprises Transform Their Workforce}

Recent initiatives have also been introduced to encourage businesses to digitalize their processes, such as the AI Singapore and SME Go Digital initiatives, and the SG Digital movement. The Government has also been actively promoting the use of technologies to strengthen workforce development in organizations and businesses.

JobKred supports a company's workforce transformation journey by helping the company identify the future-ready skills they want within their company, and by supporting the development of competency frameworks to guide skills and career development. A workforce development platform then profiles all employees, to identify and validate the skills inventory within the company, and helps the company keep a pulse on their skills development progress. Finally, personalized learning recommendations and digital career guidance help employees quickly gain skills relevant to the needs of the company.

JobKred has worked with various Singapore Government agencies to educate employers on the necessity and process of workforce transformation, and to provide a platform to help facilitate that transformation. With a tech solution, employers can quickly deploy their transformation plans to the entire organization, while saving up to $90 \%$ of cost and time compared with traditional methods. 


\section{Evaluation}

The SkillsFuture Initiative has taken the right direction and has brought about a change in the mindsets of the people. Increasingly, the national conversation is shifting from why one should engage in lifelong learning to how one can do so effectively. The range of subsidies and funding has greatly helped in the process of encouraging both businesses and workers to invest in constant upgrading.

However, the industry skills frameworks on which the Government depends to guide its plans are unfortunately static and cannot keep up with changes in the industry. As they were crafted with help from industry experts and consultants, both the industry skills maps and qualifications require manual refreshment and often lack real-time information to refer to, resulting in the inability to update quickly and forecast accurately.

JobKred has used Big Data and AI to provide targeted and personalized digital career guidance and lifelong learning to both individuals and enterprises, with focus and emphasis on jobs and skills, and with relevance to the latest industry skills demand. The track record achieved, powering Singapore's national skills and job portals; and use by the majority of universities in Singapore, as well as by employers from 15 industries ranging from small enterprises to Fortune 50 companies reflect JobKred's effectiveness and success in changing how Singapore is preparing for the future of work.

\section{Conclusion}

With the changes in the world of work, it is of rising importance that people constantly upgrade themselves to lead innovations and not be disrupted by them. Governments, businesses, and individuals should actively support this workforce transformation, and ensure that a scalable system connecting labor demand information, training, and career development is utilized to reduce lag time in workforce transformation.

Link to the presentation material: https://events.development.asia/materials/201 71213/jobkreds-technology-platform-bridging-skills-gaps. 
The views expressed in this Chapter are those of the authors and do not necessarily reflect the views and policies of the Asian Development Bank (ADB) or its Board of Governors or the governments they represent.

ADB does not guarantee the accuracy of the data included in this Chapter and accepts no responsibility for any consequence of their use. The mention of specific companies or products of manufacturers does not imply that they are endorsed or recommended by ADB in preference to others of a similar nature that are not mentioned.

By making any designation of or reference to a particular territory or geographic area, or by using the term "country" in this Chapter, ADB does not intend to make any judgments as to the legal or other status of any territory or area.

This work is available under the Creative Commons Attribution 3.0 IGO license (CC BY 3.0 IGO) https://creativecommons.org/licenses/by/3.0/igo/. By using the content of this Chapter, you agree to be bound by the terms of this license. For attribution, translations, adaptations, and permissions, please read the provisions and terms of use at https://www.adb.org/terms-use\#openac cess.

This CC license does not apply to non-ADB copyright materials in this Chapter. If the material is attributed to another source, please contact the copyright owner or publisher of that source for permission to reproduce it. ADB cannot be held liable for any claims that arise as a result of your use of the material.

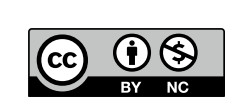

